$-166-$

\section{EFFECTS OF DILTIAZEM ON ELECTRICAL ALTERNANS OF ST SEGMENT AND VEN- TRICULAR ARRHYTHMIA INDUCED BY ACUTE CORONARY OCCLUSION}

Tomohiro Hayakawa, Yasuo Nagamoto, Kenichi Ninomiya, Sinnosuke Abe, Akio Kuroiwa

The 2nd Department of Internal Medicine, School of Medicine, University of Occupational and Environmental Health, Japan

Effects of diltiazem(Dz) on electrical alternans of ST segment (STEA) and ventricular arrhythmia (VA) during coronary occlusion and reperfusion were examined in anesthetized open chest dogs. Standard II ECG, unipolar surface ECG, His bundle electrogram, bipolar surface electrograms and bipolar monophasic action potentials (MAP) both inside (IZ) and outside (NZ) boundaries of the ischemic zone, and blood pressure were simultaneously recorded. Rigth atrial appendage was paced at a rate of $180 /$ min. Dogs were divided into two groups. Group A ( 16) incluced dogs with administration of $\mathrm{Dz} 10.02$ $\mathrm{mg} / \mathrm{kg} / \mathrm{min})$. Group $\mathrm{B}(\mathrm{n}=29)$ included dogs without $\mathrm{DZ}$. In addtion, in other 5 dogs, regional myocardial blood flow (RMBF) were measured in both ischemic center zone and border zone using $\mathrm{H}_{2}$ clearance method.

Results: In group $A$, compared with group $B$, (1) the incidence of VA, particularly VT and VF, significantly decreased during occlusion.

(2) the degree of STEA, MAP alternans and conduction delay were significantly attenuated.

(3) RMBF in both zones significantly increased before occlusion, but the decrease in RMBF during occlusion did not improved.

(4) there were no significant difference in blood pressure during occlusion between both groups. Our results suggest that the mechanism for the decrease in the incidence of VA, degree of STEA and $M A$ alternans by $D Z$ is not due to the improvement of RMBF and the decrease in pressure rate product, but may be due to the reduction of transmembrane Ca flux into ischemic myocardium.

$-167-$

EFFECTS OF ALPHA- AND BETA-BLOCKING AGENTS ON ISCHEMIA- AND REPERFUSIONINDUCED ARRHYTHMIAS

\section{-STUDIES IN THE CONSCIOUS RAT-}

K. Kinoshita, K. Tokunaga, A.S. Manning* and D.J. Hearse*

Dept. of Cardiac Surgery, Kyushu University School of Medicine and * The Rayne Institute, St. Thomas' Hospital, U.K.

Most studies on ischemia- and reperfusion-induced arrhythmias have been performed either in the isolated heart preparations or in anesthetized animals. Since the use of anesthetics and denervation can influence the severity of arrhythmias, we have developed a conscious rat preparation, in which coronary artery occlusion and also reperfusion can be achieved, and occludedzone size can be measured. Using this new preparation,. we have assessed the effects of an alpha-blocking agent, prazosin and a beta-blocking agent, atenolol on ischemia- and reperfusion-induced arrhythmias. Atenolol ( $\mathrm{lmg} / \mathrm{kg}$ body wt, given i.v. $10 \mathrm{~min}$ prior to LAD occlusion, $n=12$ ) decreased heart rate and significantly reduced the incidence of ventricular fibrillation from $63 \%(15 / 24)$ to $17 \%(2 / 12) \quad(p<$ $0.05)$. In contrast, prazosin $(0.1$ or $1 \mathrm{mg} / \mathrm{kg}$ body wt, given i.v. 10 min prior to occlusion, $n=12$ ) significantly increased heart rate. It did not alter the incidence of VF, but dramatically increased mortality from $13 \%(3 / 24)$ to $100 \%$ ( $p<$
$0.001)$ and $87 \%(p<0.001)$ during $30 \mathrm{~min}$ of ischemia, respectively. The high mortality with prazosin was associated with a high incidence of brachyarrhythmias. Atenolol also significantly reduced the incidence of reperfusion induced VF following $5 \mathrm{~min}$ of coronary occlusion from $100 \%$ $(15 / 15)$ to $58 \%(7 / 12)(p<0.05)$. All groups possessed occluded zone of similar size. Thus, in the conscious rat, atenolol affords some protection against ischemia- and reperfusion-induced $V F$, whilst at the doses studied, prazosin exacerbates arrhythmias and resultant mortality.

\section{$-168-$ \\ EFFECTS OF PREEXISTING CORONARY STENOSIS ON VENTRICULAR ARRHYTHMIAS AND ST SEGMENT ELEVATION INDUCED BY ACUTE CORONARY OCCLUSION}

Masasuke Fujita, Yasuo Nagamoto, Takashi Ohokita, Yoichiroh Furuno, Akio Kuroiwa

The 2nd Department of Internal Medicine, School of Medicine, University of Occupational and Environmental Health, Japan

After release of 1 st 5 min occlusion of left anterior descending coronary artery, 33 dogs were separated into two groups. Group A included 16 dogs with 4 hrs stenosis before 2 nd $10 \mathrm{~min}$ occlusion. Group B included 17 dogs with 4 hrs nowstenosis before it. Based on the mean value ( $12.1 \mathrm{ml} / \mathrm{min} / 100 \mathrm{~g}$ ) of regional myocardial blood flow (RMBF) in ischemic center zone(IZ) during lst occ., dogs with less than 12.1 of RMBF were selected for the analysis in both groups because those were postulated to have poor collateral flow like in human being.

Results: During 1st occ., there were no differences in RMBF in IZ, conduction delay (CD), ST segment elevation in IZ between group $A^{\prime}(n=11)$ and group B' $(\mathrm{n}=10)$.

During 2nd occ., compared with group $B^{\prime}$, results in group $A^{\prime}$ ' were as follows:

(1) RMBF in IZ was significantly increased (11.6 \pm 1.9 vs $5.7 \pm 0.7 \mathrm{ml} / \mathrm{min} / 100 \mathrm{~g}, \mathrm{p}<0.05, \mathrm{M} \pm \mathrm{SE})$. (2) $C D$ and $S T$ segment elevation were significantly reduced $(18.4 \pm 5.6$ vs $57.6 \pm 17.0 \mathrm{~ms}, \mathrm{p}<0.05$ and $5.3 \pm 2.5$ vs $16.1 \pm 4.5 \mathrm{mV}, \mathrm{p}(0.05, \mathrm{M} \pm \mathrm{SE})$.

(3) Incidence of occurrence of ventricular arrhythmias (VA) was significantly reduced.

Our results suggest that reduction of CD, ST segment elevation and incidence of VA during 2 nd occ. in group $A^{\prime}$ was due to the increase in collateral flow stimulated by the preexisting coronary stenosis.

\section{$-169-$ \\ THE EFFECT OF CORONARY REOCCLUSION ON REPERFUSION ARRHYTHMIA IN CONSCIOUS DOGS}

Hidetoshi Koga, Shiro Yamachika, Nobuto Moroki and Kunitake Hashiba

The Third Department of Internal Medicine, Nagasaki University School of Medicine

The effect of coronary reocclusion on reperfusion arrhythmia was evaluated in 31 mongrel dogs. After induction of anesthesia and left thoracotomy, the snare-type polyethylene occluder was placed around the left circumflex coronary artery. Seven days after operation coronary occlusion was produced by the occluder in the awake state, and reperfusion was carried out 1 hour after coronary occlusion. ECG was recorded continuously at slow speed and standard 
speeds using limb leads.

Reperfusion was carried out in 28 cases. Three cases died of ventricular fibrillation (VF) during coronary occlusion. Twenty seven of the 28 cases developed reperfusion arrhythmia (sustained ventricular tachycardia (VT) 15, non-sustained VT 5, VF 2 , and-frequent ventricular premature contruction (VPC) 5). Coronary reocclusion was performed within 3 minutes after reperfusion (early coronary reocclusion) in 10 cases. Sustained VT in 8 cases and frequent VPC in 2 cases all disappeared after reocclusion in 1 to 75 seconds.

Coronary reocclusion was performed in 9 cases between 20 and 30 minutes (late coronary reocclusion). Sustained VT after reperfusion in 4 cases which were temporarily suppressed by lidocaine bolus injection and reappeared in 15 to 20 minutes all disappeared in 18 to 100 seconds after reocclusion. Non-sustained VT in 4 cases all disappeared after reocclusion.

These results demonstrate that coronary reocclusion has an interrupting effect on reperfusion arrhythmia.

\section{$-170-$ \\ A STUDY OF THE ARRHYTHMOGENIC MECHANISM IN HYPOKALEMIA}

Tadanobu Takamura, Satoru Sugiyama, Takayuki Ozawa, Masayoshi Ajioka*, Taizo Kondo*, Yuuichi Ogawa

Departments of Biomedical Chemistry and Internal Medicine*, University of Nagoya.

The arrhythmogenic mechanism in dogs with hypokalemia was investigated in relation to the effect of alpha-1 blockade. Hypokalemia was induced by insertion of ion-exchange resin into colon. After the premedication of $60 \mathrm{~min}, 10 \mathrm{\mu g} / \mathrm{kg}$ of epinephrine was injected intravenously. Heart mitochondria(Mt) was prepared $5 \mathrm{~min}$ after the epinephrine injection and $\mathrm{Mt} \mathrm{Ca}^{2+}$ content was measured. The severity of arrhythmias was expressed by the arrhythmic ratio (the percentage expressed by the arrhythmic ratio (the percentage
of ventricular ectopic beats divided by the total heart rate) during $5 \mathrm{~min}$ after the epinephrine injection. In the hypokalemia group, dogs with the arrhythmic ratio of over 10 s were observed 9 out of 17. However, in the control group $(n=13)$ which was maintained normal serum $\mathrm{K}^{+}$level, only one dog showed the arrhythmic ratio of over $10 \%$. Furthermore, dogs with the lower serum $\mathrm{K}^{+}$levels showed the higher arrhythmic ratio. $\mathrm{Ca}^{2+}$ content of heart $M t$, which is considered to be the reflection of intracellular $\mathrm{Ca}^{2}$ concentration was $24.4 \pm 5.7$ nmoles/mg protein in the control group $5 \mathrm{~min}$ after the epinephrine injection, while
that from the hypokalemia group was increased to $35.0 \pm 13.4$. A good reciprocal correlation between the concentration of serum $\mathrm{K}^{+}$just before the epinephrine injection and $\mathrm{Mt} \mathrm{Ca}^{2}{ }^{+}$content was observed in the hypokalemia group $(r=-0.79)$ while $n$ the control group, no correlation was observed. Clear correlation between $\mathrm{Mt} \mathrm{Ca}^{2+}$ content and the arrhythmic ratio was also observed in the hypokalemia group. Pretreatment of bunazosin, an alpha-1 blockade, prevented effectively the increase in $\mathrm{Mt} \mathrm{Ca}^{2+}$ content, and reduced the arrhythmic ratio. These results indicate that, in hypokalemia, a relatively small dosis of epinephrine, which scarcely effects the dogs maintained with normal serum $\mathrm{K}^{+}$level, could induce the severe ventricular arrhythmias probably due to the $\mathrm{Ca}^{2}$ influx to myocardium through alpha-1 adrenergic responsiveness.

\section{Chairman}

171-176 M. Arita, Oita

177-181 J. Toyama, Nagoya

182-186 M. Hiraoka, Tokyo

187-191 S. Yasui, Yamagata

\section{$-171-$ \\ DESENSITIZATION OF ACh-INDUCED $\mathrm{K}^{+}$ CURRENT IN ATRIAL CELLS OF THE GUINEA- PIG HEART}

Toshiaki Nakajima, Yoshihisa Kurachi \& Tsuneaki Sugimoto

The 2nd Dept of Int Med, Univ of Tokyo, Tokyo

Acetylcholine ( $A C h$ ) increases $\mathrm{K}^{+}$current ( I $)$ in atrial tissues. Although it has been generally described that muscarinic increase of $\mathrm{K}^{+}$current does not desensitize during continuous application of $\mathrm{ACh}$ in cardiac tissues, we found that $I$ does desensitize. Here, we characterize the desensitization phenomenon of $I_{A C h}$ in single atrial cells of the guinea-pig. The tight-seal whole cell clamp technique was used. The pipette solution contained $100 \mathrm{uM} \mathrm{GTP}$ and $1 \mathrm{mM} . \mathrm{MgCl}_{2}$. Various concentrations of $A C h$ wre applied in the bath solution. ACh $10^{-8}-10^{-4} \mathrm{M}$ increased I dose-dependent1y. I than $10^{-} \mathrm{M}$ decreased ${ }^{-1}$ ith time after initial activation. The time-course of the decay could be divided into two exponential components. The time-constants of both components were not affected by the membrane potential but depended on the concentrations of ACh. The I steady state was $67 \%\left(10^{-6} \mathrm{M} A \mathrm{ch}\right), 53 \%($ $\left.10^{-5} \mathrm{M} \mathrm{ACh}\right) \& 43 \%\left(10^{-4} \mathrm{M}\right)$ of the peak current, respective $1 \mathrm{y}$. When $10^{-5} \mathrm{M} 6_{\mathrm{ACh}}$ was applied after perfusion of $10^{-6} \mathrm{M} \mathrm{ACh}$, the peak current evoked by $10^{-5} \mathrm{M} \mathrm{ACh}$ decreased to $68 \%$ of the control, which was coincident with the degrease of $I_{A C h}$ during perfusion of $10^{-6} \mathrm{M} \mathrm{ACh}$. We Acherpret this phenomenon as representing the desensitization of muscarinic receptors by $\mathrm{ACh}$.

$-172-$

ACETYLCHOLINE AND ADENOSINE RECEPTORS LINK WITH A $\mathrm{K}^{+}$CHANNEL VIA GTP-BINDING PROTEINS IN CARDIAC ATRIAL CELL MEMBRANE

Yoshihisa Kurachi, Toshiaki Nakajima \& Tsuneaki Sugimoto

The 2nd Dept of Int Med, Univ of Tokyo, Tokyo

Both acetylcholine ( $A C h$ ) and adenosine ( Ado) reduce the heart rate and atrio-ventricular conduction by increasing a $\mathrm{K}$ conductance of cardiac cell membrane. To clarify the molecular mechanisms underlying the effects of ACh and Ado, we examined the mode of regulation of $K$ channe 1 